\title{
Association between Body Mass Index and Gastric Cancer Risk According to Effect Modification by Helicobacter pylori Infection
}

\author{
Jieun Jang, $B S^{1,2,3}$ \\ Eun-Jung Cho, $\mathrm{PhD}^{4}$ \\ Yunji Hwang, $\mathrm{PhD}^{1,2,3}$ \\ Elisabete Weiderpass, MD, PhD5,6,7,9,9 \\ Choonghyun Ahn, MD1,2,3 \\ Jeoungbin Choi, MD1,3 \\ Soung-Hoon Chang, MD, $\mathrm{PhD}^{10}$ \\ Hai-Rim Shin, MD, PhD'11 \\ Min Kyung Lim, $\mathrm{PhD}^{12,13}$ \\ Keun-Young Yoo, MD, PhD'1, \\ Sue K. Park, MD, MPH, PhD ${ }^{1,23}$
}

*A list author's affiliations appears at the end of the paper.

Correspondence: Sue K. Park, MD, MPH, PhD Department of Preventive Medicine, Seoul National University College of Medicine, 103 Daehak-ro, Jongno-gu, Seoul 03080, Korea Tel: $82-2-740-8338$

Fax: 82-2-747-4830

E-mail: suepark@snu.ac.kr

Received March 27, 2018

Accepted November 4, 2018

Published Online November 21, 2018

*Jieun Jang and Eun-Jung Cho contributed equally to this work.

\begin{abstract}
Purpose
Few studies investigated roles of body mass index (BMI) on gastric cancer (GC) risk according to Helicobacter pylori infection status. This study was conducted to evaluate associations between $\mathrm{BMI}$ and GC risk with consideration of $H$. pylori infection information.
\end{abstract}

\section{Materials and Methods}

We performed a case-cohort study ( $n=2,458)$ that consists of a subcohort $(n=2,193$ including 67 GC incident cases) randomly selected from the Korean Multicenter Cancer Cohort (KMCC) and 265 incident GC cases outside of the subcohort. H. pylori infection was assessed using an immunoblot assay. GC risk according to BMI was evaluated by calculating hazard ratios (HRs) and their 95\% confidence intervals ( $95 \% \mathrm{Cls}$ ) using weighted Cox hazard regression model.

\section{Results}

Increased GC risk in lower BMI group $\left(<23 \mathrm{~kg} / \mathrm{m}^{2}\right)$ with marginal significance (HR, 1.32; $95 \% \mathrm{Cl}, 0.98$ to 1.77 ) compared to the reference group (BMI of $23-24.9 \mathrm{~kg} / \mathrm{m}^{2}$ ) was observed. In the H. pylori non-infection, both lower $\left(<23 \mathrm{~kg} / \mathrm{m}^{2}\right)$ and higher BMI $\left(\geq 25 \mathrm{~kg} / \mathrm{m}^{2}\right)$ showed non-significantly increased GC risk (HR, $10.82 ; 95 \% \mathrm{Cl}, 1.25$ to 93.60 and $\mathrm{HR}$, 11.33; $95 \% \mathrm{Cl}, 1.13$ to 113.66 , respectively). However, these U-shaped associations between $\mathrm{BMI}$ and GC risk were not observed in the group who had ever been infected by H. pylori.

\section{Conclusion}

This study suggests the U-shaped associations between BMI and GC risk, especially in subjects who had never been infected by $H$. pylori.

\section{Introduction}

Globally, gastric cancer (GC) holds the fourth and fifth rank of cancer incidence in males and females, respectively and is the third leading cause of cancer death in both sexes worldwide [1]. With the combination of high incidence and poor survival, GC is one of main contributor to the cancer burdens worldwide [2]. Korea is one of the countries showing highest GC incidence rate (age-standardized rate [ASR],

\section{Key words}

Stomach neoplasms, Body mass index, Helicobacter pylori, Cohort studies, Case-cohort, Effect modification 
ern populations showed positive association between high body mass index (BMI) and gastric cardia cancer incidence [6-8]. In a recent meta-analysis, summary relative risk (SRR) of gastric cardia caner in obese group (BMI $\geq 30 \mathrm{~kg} / \mathrm{m}^{2}$ ) was reported as 1.82 (95\% confidence interval [CI], 1.32 to 2.49 ) compared to normal weight group (BMI of $18.5-24.9 \mathrm{~kg} / \mathrm{m}^{2}$ ). However, evidence on association between obesity and gastric non-cardia cancer (SRR, 1.00; 95\% CI, 0.87 to 1.15 ) was not found in the same study [9]. Controversially, recent large scaled cohort studies reported elevated GC risk in low BMI group $\left(\mathrm{BMI}<22 \mathrm{~kg} / \mathrm{m}^{2}\right)$ [10] and significantly decreased risk of gastric non-cardia cancer in population with high BMI $\left(\geq 23 \mathrm{~kg} / \mathrm{m}^{2}\right)$ than low BMI group $\left(<20.32 \mathrm{~kg} / \mathrm{m}^{2}\right)$ [11] , hence further verification of relationship between BMI and GC is still needed.

The proportion of gastric cardia cancer is higher in the Western population than amongst Asians [12,13]. Contrary to the Western population, gastric non-cardia cancer comprises a larger proportion in the East Asian populations, and particularly in the Korean population, gastric non-cardia cancers are responsible for over 95\% of total GC [14].

Moreover, the prevalence of Helicobacter pylori infection, a group I carcinogen defined by the International Agency for Research on Cancer (IARC) [15], is higher in Asian countries compared to Western countries. The East Asian strains of $H$. pylori were also reported to be more virulent to gastric carcinogenesis than the Western strains of $H$. pylori [16]. Several studies reported the inverse association between $H$. pylori infection prevalence and BMI level [17]. These results infer that underweight population probably have high risk of gastric non-cardia cancer due to high prevalence of $H$. pylori infection. However, previous studies did not in fact measure H. pylori infection status as a potential confounder on the association between gastric non-cardia cancer risk and BMI; thus the association between BMI and gastric non-cardia cancer according to $H$. pylori infection is not well-characterized.

Based on the differences in gastric non-cardia cancer incidence rates, prevalence of $H$. pylori infection and its strains, and the proportions of the population with extremes of BMI between the Asian countries and Western countries, we realized the necessity to focus on the association between low BMI and GC risk in Asia. Hence, we carried out a study (1) to assess GC risk according to BMI while controlling the potential confounding effect of $H$. pylori infection, (2) to investigate the potential effect modification by $H$. pylori infection on the association between BMI and GC risk, (3) to evaluate potential difference in association between $H$. pylori and GC risk according to BMI level in the case-cohort study which is based on the Korean Multicenter Cancer cohort (KMCC).

\section{Materials and Methods}

\section{Data and study subjects}

This study was designed within the population-based prospective KMCC which is constructed to assess risk factors related to cancer incidence and mortality in Korea. The KMCC participants were recruited from the four urban and rural areas (Haman, Chungju, Uljin, and Pohang) between 1993 and 2004. All participants signed an informed consent form [18].

This study was conducted in two observational study designs, a prospective cohort study and a case-cohort study. We tried to assess $H$. pylori infection status in order to adjust potential confounding effect of $H$. pylori. Because entire cohort was too large to test $H$. pylori infection status of all subjects, we choose case-cohort study design which is efficient in the aspect of reducing time and cost by selecting subset of entire cohort subjects.

Flowchart of subject selection on total cohort and casecohort study is shown in the S1 Fig. After excluding the subjects without information on height or weight measures, 19,016 subjects were defined as the total cohort study population and 485 incident GC cases were identified in the total cohort study subjects. Plasma samples for assessing H. pylori infection status had been collected from 9,402 subjects including 332 incident GC cases among 19,016 total cohort subjects. We stratified these 9,402 subjects with plasma sample according to sex and age (10-year interval). Then, we randomly sampled $24 \%$ of subjects in each strata to constitute the subcohort by reflecting sex and age structure of the KMCC. After excluding subjects with insufficient or poor condition of plasma sample, a total of 2,200 subjects (about 23\%) were defined as eligible subjects for subcohort in this study. Number of GC incident cases within the subcohort and outside of the subcohort were 67 and 265 cases, respectively.

We assessed H. pylori infection status and IgG seropositivity to $H$. pylori virulence factors of eligible subjects for subcohort $(n=2,200)$ and GC incidence cases outside of the subcohort $(n=265)$. There were seven subjects whose H. pylori infection status or $\mathrm{IgG}$ antibody to virulence factors were not measured due to insufficient sample volume or inadequate sample condition. Hence, a total of 2,193 subjects were defined as the subcohort population after excluding subjects whose $H$. pylori infection status or $\operatorname{IgG}$ antibody to virulence factors were not measured. Finally, a total number of 2,458 case-cohort subjects were denoted by integrating the subcohort subjects $(n=2,193)$ and GC incident cases outside of the subcohort $(\mathrm{n}=265)$. 


\section{Outcome assessment}

Incident GC cases in the KMCC were ascertained through the record linkage between the KMCC data and the national cancer registry data. Death certificate only cases were also confirmed through linking the national death certificate of the National Statistical Office to the KMCC data. A total of 508 incident GC cases among the total KMCC participants were identified until December 31, 2013. After excluding GC cases without information on height or weight, 485 GC cases were left in the total cohort study. We measured H. pylori infection status of case-cohort study subjects. Because we could not assess H. pylori infection status of 153 GC cases due to insufficient volume or unstable condition of plasma samples, a total of 332 GC cases with information of H. pylori infection status were included in the case-cohort study.

\section{Exposure assessment: BMI}

Information on individual characteristics such as demographic factors, lifestyle factors, and past medical history was collected using a standardized interview-based questionnaire. Anthropometric indices such as height, weight, waist and hip circumferences were also measured by the study team. Height, the perpendicular distance between the top of head and the heel after taking off shoes and standing with their back against the wall straightly, and weight of study subjects were measured by skilled investigators on the same day of questionnaire interview at the cohort enrollment. Measurements of height and weight were conducted twice and the mean value was used in this study.

BMI $\left(\mathrm{kg} / \mathrm{m}^{2}\right)$ was computed in accordance with its definition: weight $(\mathrm{kg})$ divided by square of the height $\left(\mathrm{m}^{2}\right)$. Because World Health Organization (WHO) BMI classification was proposed to reflect risk for mortality and non-communicable diseases related to death, such as type 2 diabetes and cardiovascular disease [19], other BMI criteria might be more informative to indicate GC risk. Recent cohort studies also reported significant change in GC risk in group with BMI around of $23.0 \mathrm{~kg} / \mathrm{m}^{2}$, hence we applied modified criterion of BMI in several ways as follows:

$$
\begin{aligned}
\text { (a) } & <18.5,18.5-22.9,23-24.9 \text { (reference), 25-29.9, and } \\
& \geq 30 \mathrm{~kg} / \mathrm{m}^{2} \\
\text { (b) } & <23,23-24.9 \text { (reference), and } \geq 25 \mathrm{~kg} / \mathrm{m}^{2} \\
\text { (c) } & <18.5,18.5-22.4,22.5-24.9 \text { (reference), } 25-27.4 \text {, and } \\
& \geq 27.5 \mathrm{~kg} / \mathrm{m}^{2} \\
\text { (d) } & <22.5,22.5-24.9 \text { (reference), and } \geq 25 \mathrm{~kg} / \mathrm{m}^{2} \\
\text { (e) } & <23 \mathrm{~kg} / \mathrm{m}^{2} \text { and } \geq 23 \mathrm{~kg} / \mathrm{m}^{2} \text { (reference) }
\end{aligned}
$$

When we apply BMI category (a) to analysis, too small number of GC cases were included in one category. Thus, we made BMI category (b) by combining each of two lower and two higher BMI groups than reference group as one group. Because small number of GC cases were included in the reference group of BMI category (a) and (b) in the case-cohort study, we conducted sensitivity analysis by slightly changing criteria of BMI category (a) as BMI category (c). BMI category (d) was also determined by combining each of two lower and two higher BMI groups in category (c) as one BMI group.

\section{Exposure assessment: Measurement of $H$. pylori infec- tion status}

Specimens including serum, plasma, buffy coat, packed red blood cell, and spot urine were also collected from the KMCC participants and stored in standardized stable condition $\left(-70^{\circ} \mathrm{C}\right.$ for blood samples and $-20^{\circ} \mathrm{C}$ for spot urine samples) [18]. Cytotoxin-associated gene A (CagA) and vacuolating cytotoxin $\mathrm{A}$ (VacA) has been known for virulence factors of H. pylori. CagA and VacA have been reported that these virulence factors are associated with cellular responses related to carcinogenesis such as excessive cell proliferation, inhibition of apoptosis, and excessive inflammatory responses [20]. Hence, we assessed seropositivity of CagA and VacA IgG along with H. pylori infection status.

Because plasma sample collected at cohort enrollment were the sole specimen to assess $H$. pylori infection status and the invasive endoscopy (a gold standard of $H$. pylori test) and a noninvasive reliable Urea Breath test was not easy to apply in the setting of the community population group, we used immunoblot assay, the Helico Bolt 2.1TM (MP Biomedicals Asia Pacific, Singapore), to test $H$. pylori infection and seropositivity on CagA and VacA IgG. The validity of Helico Blot 2.1 was fairly good for sensitivity, $99 \%$; for specificity, 98\% [21].

Procedure for immunoblot assay is as follows: nitrocellulose strips were diluted with $2 \mathrm{~mL}$ of diluted wash buffer and were incubated for 5 minutes at room temperature on a rocking platform. The plasma samples were collected at baseline survey and frozen at $-70^{\circ} \mathrm{C}$ until analysis; $2 \mathrm{~mL}$ of blotting buffer was added to each well containing $2 \mu \mathrm{L}$ of plasma or positive/negative controls. After incubating for 1 hour at room temperature on a rocking platform, the plates were washed three times with $2 \mathrm{~mL}$ of diluted wash buffer allowing 5 minutes soak on the rocking platform between each wash. Two milliliters of working conjugate solution was added to the wells and was incubated for 1 hour at room temperature. After aspirating the conjugate and washing three times, $2 \mathrm{~mL}$ of substrate solutions was added. Plates were shaken at room temperature for 15 minutes and washed three times, the same as above. Each strip was interpreted according to the recommended criteria in manufacturer's instruction. 


\section{Statistical analysis}

Basic characteristics between group with $\mathrm{BMI}<23 \mathrm{~kg} / \mathrm{m}^{2}$ and group with $B M I \geq 23 \mathrm{~kg} / \mathrm{m}^{2}$ were compared by conducting the Pearson's chi-square test for categorical variables and Student $\mathrm{t}$ test for numerical variables in both total cohort and case-cohort study.

Differences in the mean of age, height, weight, and cohort follow-up time (year) along with frequency of sex, GC cases, education years ( $<12$ years vs. $\geq 12$ years), ever smoking, more or equal to 400 cigarettes (yes vs. no), alcohol drinking (ever vs. never drinker), history of gastritis, H. pylori ever infection (yes vs. no), CagA-secreting H. pylori infection (positive vs. negative) between the low and high BMI groups were considered.

Hazard ratios (HRs) and their 95\% CIs of GC incidence according to BMI level in the total cohort population were calculated by using the Cox proportional hazards regression models. We included age, sex, and year at cohort enrollment in the Cox hazard regression model and variables showing statistically significant differences between low and high BMI groups (education, cigarette smoking, and alcohol drinking) were also considered for adjustment in the total cohort study.

In case of the case-cohort study, GC risks according to BMI level or H. pylori infection were computed using the weighted Cox proportional hazard model. H. pylori infection status was additionally adjusted in the weighted Cox proportional haz- ard regression model when GC risk according to BMI level was evaluated. We used the Barlow's weighting method in the case-cohort study [22]. Weight of all GC cases in the casecohort study were assigned as 1 and weight of controls were assigned as inverse of sample fraction defined as the proportion of subcohort controls within the total cohort controls.

We also conducted stratified analysis by $H$. pylori infection status to assess effect modification by H. pylori on the association between BMI and GC risk. Subgroup of individuals with $H$. pylori infection was further considered according to CagA and VacA virulence factors (group with CagA-secreting H. pylori infection, CagA+; group with both CagA-secreting H. pylori and VacA-secreting H. pylori infection, CagA+ $\mathrm{VacA}+)$.

We also assessed differences in GC risk according to $H$. pylori infection among BMI categories $\left(<23 \mathrm{~kg} / \mathrm{m}^{2}, 23-24.9\right.$ $\mathrm{kg} / \mathrm{m}^{2}$, and $\geq 25 \mathrm{~kg} / \mathrm{m}^{2}$ ) to investigate effect modification by $\mathrm{BMI}$ on the association between $H$. pylori and GC risk.

Sensitivity analyses for cardia and non-cardia GC development were performed. Non-cardia GC category included GC cases with unspecified locations and missing T-code since non-cardia GC consisted of more than $95 \%$ of total GC cases in Korean population [14].

All statistical analysis was two-sided with alpha error of 5\% and were performed using SAS software ver. 9.4 (SAS Institute Inc., Cary, NC).

Table 1. General characteristics of cohort and case-cohort study subjects within the Korean Multicenter Cancer Cohort (KMCC), 1993-2004

\begin{tabular}{|c|c|c|c|c|c|c|}
\hline \multirow[b]{2}{*}{ Characteristic } & \multicolumn{3}{|c|}{ Total cohort $(n=19,016)$} & \multicolumn{3}{|c|}{ Case-cohort $(n=2,458)$} \\
\hline & $\begin{array}{c}\left.\text { Low BMI }{ }^{2}\right) \\
(\mathrm{n}=8,645)\end{array}$ & $\begin{array}{c}\text { High BMI }^{a)} \\
(\mathrm{n}=10,371)\end{array}$ & p-value & $\begin{array}{c}\left.\text { Low BMI }{ }^{a}\right) \\
(n=1,168)\end{array}$ & $\begin{array}{c}\text { High BMI }^{a)} \\
(n=1,290)\end{array}$ & p-value \\
\hline Age (yr) & $53.6 \pm 16.5$ & $53.8 \pm 12.4$ & 0.28 & $56.8 \pm 14.7$ & $54.1 \pm 12.1$ & $<0.01$ \\
\hline Height (cm) & $158.0 \pm 8.9$ & $157.1 \pm 8.8$ & $<0.01$ & $158.9 \pm 9.0$ & $157.8 \pm 8.9$ & $<0.01$ \\
\hline Weight (kg) & $52.0 \pm 7.1$ & $64.1 \pm 8.7$ & $<0.01$ & $52.6 \pm 7.2$ & $64.5 \pm 8.8$ & $<0.01$ \\
\hline Follow-up (yr) & $12.9(9.9-16.5)$ & $12.4(9.9-16.4)$ & 0.93 & $12.9(7.4-15.4)$ & $13.2(10.4-17.3)$ & $<0.01$ \\
\hline Male & $3,905(45.2)$ & $3,714(35.8)$ & $<0.01$ & $650(55.7)$ & $554(43.0)$ & $<0.01$ \\
\hline GC cases & $277(3.2)$ & $208(2.0)$ & $<0.01$ & $193(16.5)$ & $138(10.8)$ & $<0.01$ \\
\hline Education $\geq 12 \mathrm{yr}$ & 1,122 & $1,456(14.2)$ & 0.04 & 139 (11.9) & $190(14.8)$ & 0.04 \\
\hline Ever smokers ${ }^{\mathrm{b})}$ & $3,670(43.1)$ & $3,244(31.7)$ & $<0.01$ & $594(51.1)$ & $470(36.8)$ & $<0.01$ \\
\hline Ever alcohol drinkers & $3,759(44.4)$ & $4,124(40.4)$ & $<0.01$ & $568(48.7)$ & $550(43.0)$ & $<0.01$ \\
\hline History of gastritis & $1,600(21.7)$ & $1,788(20.1)$ & 0.78 & $160(21.3)$ & $152(19.2)$ & 0.31 \\
\hline Helicobacter pylori-infected & - & - & & $996(85.3)$ & $1,108(85.9)$ & 0.66 \\
\hline $\mathrm{Cag} \mathrm{A}+H$. pylori-infected & - & - & & $952(81.5)$ & $1,061(82.3)$ & 0.63 \\
\hline
\end{tabular}

Values are presented as mean \pm standard deviation, median (IQR) for continuous variables and number $(\%)$ for category vari-

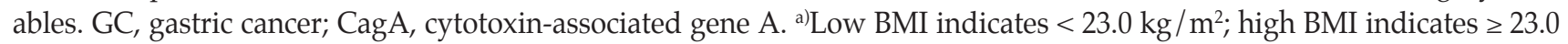
$\mathrm{kg} / \mathrm{m}^{2}$, ${ }^{\mathrm{b}}$ Ever smoking is defined as past and current smoking more or equal to 400 cigarettes. 
Table 2. Association between BMI and GC risk in the total cohort and case-cohort study within the KMCC, 1993-2004

\begin{tabular}{|c|c|c|c|c|c|c|}
\hline \multirow[b]{2}{*}{ BMI $\left(\mathrm{kg} / \mathrm{m}^{2}\right)$} & \multicolumn{3}{|c|}{ GC development } & \multicolumn{3}{|c|}{ Non-cardia GC development ${ }^{\mathrm{b}}$} \\
\hline & $\begin{array}{c}\text { Person- } \\
\text { year }\end{array}$ & No. & $\left.\operatorname{HR}(95 \% \mathrm{CI})^{\mathrm{a}}\right)$ & $\begin{array}{c}\text { Person- } \\
\text { year }\end{array}$ & No. & $\operatorname{HR}(95 \% \mathrm{CI})^{\mathrm{a})}$ \\
\hline \multicolumn{7}{|c|}{ Total cohort $(n=19,016)$} \\
\hline$<18.5$ & 10,903 & 29 & $1.36(0.89-2.08)$ & 10,903 & 29 & $1.41(0.92-2.17)$ \\
\hline $18.5-22.9$ & 100,613 & 248 & $1.38(1.08-1.76)$ & 100,559 & 239 & $1.38(1.08-1.77)$ \\
\hline $23.0-24.9$ & 57,776 & 90 & 1.00 & 57,758 & 87 & 1.00 \\
\hline $25.0-29.9$ & 67,418 & 107 & $1.13(0.85-1.50)$ & 67,395 & 105 & $1.15(0.86-1.53)$ \\
\hline$\geq 30.0$ & 8,515 & 11 & $1.18(0.63-2.20)$ & 8,515 & 11 & $1.21(0.64-2.27)$ \\
\hline$<18.5$ & 10,903 & 29 & $1.36(0.89-2.08)$ & 10,903 & 29 & $1.41(0.92-2.17)$ \\
\hline $18.5-22.9$ & 100,613 & 248 & $1.38(1.08-1.76)$ & 100,559 & 239 & $1.38(1.08-1.77)$ \\
\hline $23.0-24.9$ & 57,776 & 90 & 1.00 & 57,758 & 87 & 1.00 \\
\hline $25.0-27.4$ & 48,060 & 76 & $1.11(0.82-1.51)$ & 48,038 & 74 & $1.12(0.82-1.53)$ \\
\hline$\geq 27.5$ & 27,873 & 42 & $1.18(0.81-1.70)$ & 27,873 & 42 & $1.21(0.84-1.75)$ \\
\hline$<23.0$ & 111,516 & 277 & $1.38(1.08-1.75)$ & 111,462 & 268 & $1.38(1.08-1.77)$ \\
\hline $23.0-24.9$ & 57,776 & 90 & 1.00 & 57,758 & 87 & 1.00 \\
\hline$\geq 25.0$ & 75,933 & 118 & $1.14(0.86-1.50)$ & 75,910 & 116 & $1.15(0.87-1.52)$ \\
\hline \multicolumn{7}{|c|}{ Case-cohort $(n=2,458)$} \\
\hline$<18.5$ & 1,156 & 23 & $1.22(0.74-2.01)$ & 1,156 & 23 & $1.28(0.77-2.12)$ \\
\hline $18.5-22.9$ & 12,259 & 170 & $1.33(0.99-1.79)$ & 12,227 & 163 & $1.32(0.98-1.79)$ \\
\hline $23.0-24.9$ & 7,208 & 62 & 1.00 & 7,204 & 60 & 1.00 \\
\hline $25.0-29.9$ & 8,547 & 71 & $1.08(0.77-1.52)$ & 8,524 & 69 & $1.08(0.76-1.53)$ \\
\hline$\geq 30.0$ & 903 & 6 & $1.01(0.43-2.36)$ & 903 & 6 & $1.02(0.44-2.39)$ \\
\hline$<18.5$ & 1,156 & 23 & $1.22(0.74-2.01)$ & 1,156 & 23 & $1.28(0.77-2.12)$ \\
\hline $18.5-22.9$ & 12,259 & 170 & $1.33(0.99-1.79)$ & 12,227 & 163 & $1.32(0.98-1.79)$ \\
\hline $23.0-24.9$ & 7,208 & 62 & 1.00 & 7,204 & 60 & 1.00 \\
\hline $25.0-27.4$ & 6,094 & 51 & $1.11(0.76-1.61)$ & 6,071 & 49 & $1.10(0.75-1.61)$ \\
\hline$\geq 27.5$ & 3,356 & 26 & $1.01(0.63-1.61)$ & 3,356 & 26 & $1.03(0.65-1.65)$ \\
\hline$<23.0$ & 13,415 & 193 & $1.32(0.98-1.77)$ & 13,383 & 186 & $1.32(0.98-1.78)$ \\
\hline $23.0-24.9$ & 7,208 & 62 & 1.00 & 7,204 & 60 & 1.00 \\
\hline$\geq 25.0$ & 9,450 & 77 & $1.07(0.77-1.51)$ & 9,427 & 75 & $1.08(0.76-1.52)$ \\
\hline
\end{tabular}

BMI, body mass index; GC, gastric cancer; KMCC, Korean Multicenter Cancer Cohort; HR, hazard ratio; CI, confidence

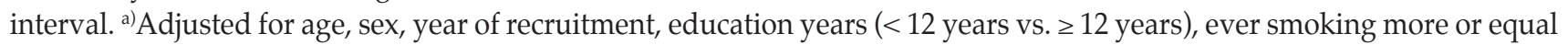
to 400 cigarettes (yes vs. no), and alcohol drinking status (yes vs. no), b) Non-cardia GC including unspecified cases (9\% of total GC cases). The results for cardia GC development were not presented due to non-estimation of parameter estimators and their $95 \%$ CIs by sparse cardia GC cases $(n=14)$.

\section{Ethical statement}

This study protocol was approved by the institutional review boards of Seoul National University Hospital (H-0110-084-002 and H-1310-082-528) and performed in accordance with the principles of the Declaration of Helsinki. Written informed consents were obtained.

\section{Results}

\section{Characteristics of study subjects}

The general characteristics were presented in Table 1. Subjects in the high BMI group were more likely to be women, have a high level of education compared to subjects in the 
Table 3. Association with body mass index for GC risk by Helicobacter pylori infection in the case-cohort study within the KMCC, 1993-2004

\begin{tabular}{|c|c|c|c|c|c|c|}
\hline \multirow[b]{2}{*}{ BMI $\left(\mathrm{kg} / \mathrm{m}^{2}\right)$} & \multicolumn{3}{|c|}{ GC development } & \multicolumn{3}{|c|}{ Non-cardia GC development ${ }^{\text {a) }}$} \\
\hline & $\begin{array}{l}\text { Person- } \\
\text { year }\end{array}$ & No. & $\begin{array}{l}\text { Stratification } \\
\text { HR }(95 \% \text { CI })^{b)}\end{array}$ & $\begin{array}{l}\text { Person- } \\
\text { year }\end{array}$ & No. & $\begin{array}{l}\text { Stratification } \\
\text { HR }(95 \% \text { CI })^{b}\end{array}$ \\
\hline \multicolumn{7}{|c|}{ Never H. pylori infected } \\
\hline$<23.0$ & 2,017 & 12 & $10.82(1.25-93.60)$ & 2,017 & 12 & $12.07(1.34-108.39)$ \\
\hline $23.0-24.9$ & 1,071 & 1 & 1.00 & 1,071 & 1 & 1.00 \\
\hline$\geq 25.0$ & 1,358 & 7 & $11.33(1.13-113.66)$ & 1,345 & 6 & $9.95(0.91-108.31)$ \\
\hline \multicolumn{7}{|c|}{ Ever H. pylori infected } \\
\hline$<23.0$ & 11,398 & 181 & $1.26(0.93-1.70)$ & 11,366 & 174 & $1.26(0.93-1.71)$ \\
\hline $23.0-24.9$ & 6,137 & 61 & 1.00 & 6,133 & 59 & 1.00 \\
\hline$\geq 25.0$ & 8,091 & 70 & $1.03(0.71-1.40)$ & 8,082 & 69 & $1.05(0.72-1.44)$ \\
\hline \multicolumn{7}{|c|}{ H. pylori+CagA+ } \\
\hline$<23.0$ & 10,886 & 174 & $1.26(0.93-1.72)$ & 10,855 & 167 & $1.26(0.92-1.72)$ \\
\hline $23.0-24.9$ & 5,895 & 59 & 1.00 & 5,891 & 57 & 1.00 \\
\hline$\geq 25.0$ & 7,762 & 68 & $1.12(0.72-1.65)$ & 7,753 & 67 & $1.03(0.72-1.48)$ \\
\hline \multicolumn{7}{|l|}{ CagA+VacA+ } \\
\hline$<23.0$ & 8,494 & 126 & $1.46(1.01-2.11)$ & 8,468 & 120 & $1.44(0.99-2.10)$ \\
\hline $23.0-24.9$ & 4,866 & 41 & 1.00 & 4,862 & 40 & 1.00 \\
\hline$\geq 25.0$ & 6,397 & 51 & $1.14(0.75-1.72)$ & 6,388 & 50 & $1.14(0.75-1.74)$ \\
\hline
\end{tabular}

GC, gastric cancer; KMCC, Korean Multicenter Cancer Cohort; BMI, body mass index; CagA+, cytotoxin-associated gene A (CagA)-secreting H. pylori infection; CagA+VacA+, both CagA-secreting H. pylori and vacuolating cytotoxin A (VacA)-

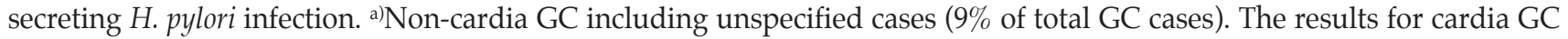
development were not presented due to non-estimation of parameter estimators and their $95 \%$ CIs by sparse cardia GC cases $(\mathrm{n}=14),{ }^{\mathrm{b}}$ Adjusted for age, sex, year of recruitment, education years ( $<12$ years vs. $\geq 12$ years), ever smoking more or equal to 400 cigarettes (yes vs. no), and alcohol drinking status (yes vs. no).

low BMI group. A relatively low proportion of ever smokers and ever drinkers were found in the high BMI group compared to the low BMI group. In general, we also confirmed the consistent results in both total cohort and case-cohort population. Additional difference of age in the total cohort and difference of follow-up period in the case-cohort study were found.

\section{GC risk according to BMI level in the total cohort study}

GC risk according to BMI categories in the total cohort is presented in Table 2. There was an increased GC risk in groups with BMI $<18.5 \mathrm{~kg} / \mathrm{m}^{2}$ or of $18.5-22.9 \mathrm{~kg} / \mathrm{m}^{2} \mathrm{com}-$ pared to the reference group (BMI of $23-24.9 \mathrm{~kg} / \mathrm{m}^{2}$ ) in the total cohort study (HR, 1.36; 95\% CI, 0.89 to 2.08 for group with $\mathrm{BMI}<18.5 \mathrm{~kg} / \mathrm{m}^{2}$ and $\mathrm{HR}, 1.38 ; 95 \% \mathrm{CI}, 1.08$ to 1.76 for group with BMI of $18.5-22.9 \mathrm{~kg} / \mathrm{m}^{2}$, respectively; however, it was non-significant in group with $B M I<18.5 \mathrm{~kg} / \mathrm{m}^{2}$.

In contrast, there was no statistically significant associations between BMI $\geq 25 \mathrm{~kg} / \mathrm{m}^{2}$ and GC risk (HR, 1.13; 95\% CI, 0.85 to 1.50 for group with BMI $25-29.9 \mathrm{~kg} / \mathrm{m}^{2}$ and HR,
1.18; $95 \%$ CI, 0.63 to 2.20 for group with $\mathrm{BMI} \geq 25 \mathrm{~kg} / \mathrm{m}^{2}$, respectively).

\section{GC risk according to BMI level in the case-cohort study}

We also assessed GC risk according to BMI with additional adjustment of $H$. pylori infection in the case-cohort study (Table 2). Similar results to the total cohort study on the association between BMI and GC risk were observed in the case-cohort study. Compared to the reference group (BMI of $\left.23-24.9 \mathrm{~kg} / \mathrm{m}^{2}\right)$, group with BMI of $<18.5 \mathrm{~kg} / \mathrm{m}^{2}$ or $18.5-22.9$ $\mathrm{kg} / \mathrm{m}^{2}$ were associated with increased GC risk (HR, 1.22; 95\% CI, 0.74 to 2.01 for group with BMI $<18.5 \mathrm{~kg} / \mathrm{m}^{2}$ and HR, 1.33; $95 \%$ CI, 0.99 to 1.79 for group with BMI of 18.5-22.9 $\mathrm{kg} / \mathrm{m}^{2}$, respectively), although the associations were not statistically significant.

\section{Effect modification by $\mathrm{H}$. pylori infection on associations between BMI and GC risk in the case-cohort study}

Further, we performed analysis on the association between 
Table 4. The association between Helicobacter pylori infection and GC risk by BMI level in the case-cohort study within the KMCC, 1993-2004

\begin{tabular}{|c|c|c|c|c|c|c|}
\hline & \multicolumn{3}{|c|}{ GC development } & \multicolumn{3}{|c|}{ Non-cardia GC development $t^{\text {a) }}$} \\
\hline & $\begin{array}{l}\text { Person- } \\
\text { year }\end{array}$ & No. & $\begin{array}{l}\text { Stratification } \\
\text { HR }(95 \% \mathrm{CI})^{\mathrm{b}}\end{array}$ & $\begin{array}{l}\text { Person- } \\
\text { year }\end{array}$ & No. & $\begin{array}{l}\text { Stratification } \\
\text { HR }\left(95 \% \text { CI) }{ }^{b}\right)\end{array}$ \\
\hline \multicolumn{7}{|l|}{$\mathrm{BMI}<23.0 \mathrm{~kg} / \mathrm{m}^{2}$} \\
\hline Never infected & 2,017 & 12 & 1.00 & 2,017 & 12 & 1.00 \\
\hline Ever infected & 11,398 & 181 & $2.04(1.13-3.70)$ & 11,366 & 174 & $1.99(1.10-3.62)$ \\
\hline H. pylori+CagA+ & 10,886 & 174 & $2.06(1.14-3.74)$ & 10,855 & 167 & $2.01(1.11-3.65)$ \\
\hline CagA+VacA+ & 8,494 & 126 & $2.03(1.11-3.72)$ & 8,468 & 120 & $1.97(1.08-3.62)$ \\
\hline \multicolumn{7}{|l|}{ BMI $23.0-24.9 \mathrm{~kg} / \mathrm{m}^{2}$} \\
\hline Never infected & 1,071 & 1 & 1.00 & 1,071 & 1 & 1.00 \\
\hline Ever infected & 6,137 & 61 & $10.52(1.44-76.67)$ & 6,133 & 59 & $9.98(1.37-72.78)$ \\
\hline H. pylori+CagA+ & 5,895 & 59 & $10.38(1.42-75.70)$ & 5,891 & 57 & $9.84(1.35-71.84)$ \\
\hline CagA+VacA + & 4,866 & 41 & $12.17(1.63-90.02)$ & 4,862 & 40 & $11.59(1.55-86.69)$ \\
\hline \multicolumn{7}{|l|}{$\mathrm{BMI} \geq 25.0 \mathrm{~kg} / \mathrm{m}^{2}$} \\
\hline Never infected & 1,358 & 7 & 1.00 & 1,345 & 6 & 1.00 \\
\hline Ever infected & 8,091 & 70 & $1.73(0.78-3.82)$ & 8,082 & 69 & $2.02(0.86-4.72)$ \\
\hline H. pylori+CagA+ & 7,762 & 68 & $1.80(0.81-4.00)$ & 7,753 & 67 & $2.11(0.90-4.94)$ \\
\hline CagA+VacA+ & 6,397 & 51 & $1.73(0.76-3.93)$ & 6,388 & 50 & $2.03(0.85-4.87)$ \\
\hline
\end{tabular}

GC, gastric cancer; BMI, body mass index; KMCC, Korean Multicenter Cancer Cohort; HR, hazard ratio; CI, confidence interval; $\mathrm{CagA}+$, cytotoxin-associated gene A (CagA)-secreting H. pylori infection; $\mathrm{CagA+VacA+,} \mathrm{both} \mathrm{CagA-secreting} H$. pylori and vacuolating cytotoxin A (VacA)-secreting H. pylori infection. ${ }^{\text {a }}$ Non-cardia GC including unspecified cases $(9 \%$ of total GC cases). The results for cardia GC development were not presented due to non-estimation of parameter estimators and their $95 \%$ CIs by sparse cardia GC cases $(n=14)$, b) Adjusted for age, sex, year of recruitment, education years $(<12$ years vs. $\geq 12$ years), ever smoking more or equal to 400 cigarettes (yes vs. no), and alcohol drinking status (yes vs. no).

BMI and GC risk stratified by H. pylori infection status and CagA-secreting H. pylori infection status (Table 3). BMI $<23$ $\mathrm{kg} / \mathrm{m}^{2}$ and $\geq 25 \mathrm{~kg} / \mathrm{m}^{2}$ were associated with increased GC risk (HR, 10.82; $95 \% \mathrm{CI}, 1.25$ to 93.60 for $\mathrm{BMI}<23 \mathrm{~kg} / \mathrm{m}^{2}$ and $\mathrm{HR}, 11.33$; $95 \% \mathrm{CI}, 1.13$ to 113.66 for BMI $\geq 25 \mathrm{~kg} / \mathrm{m}^{2}$, respectively) amongst subjects without $H$. pylori infection. In contrast, there were no statistically significant increase in GC risk in the group with $\mathrm{BMI}<23 \mathrm{~kg} / \mathrm{m}^{2}$ and $\geq 25 \mathrm{~kg} / \mathrm{m}^{2}$ who were H. pylori positive (HR, 1.26; $95 \% \mathrm{CI}, 0.93$ to 1.70 for $\mathrm{BMI}<23$ $\mathrm{kg} / \mathrm{m}^{2}$ and $\mathrm{HR}, 1.03 ; 95 \% \mathrm{CI}, 0.71$ to 1.40 for $\mathrm{BMI} \geq 25 \mathrm{~kg} / \mathrm{m}^{2}$, respectively).

Because only one GC cases were included in the reference group, we conducted sensitivity analysis after changing reference group as subjects with BMI of $22.5-24.9 \mathrm{~kg} / \mathrm{m}^{2}$ (S2 Table). Similar U-shaped association between BMI and GC risk in subjects who were not infected by H. pylori was found even when we changed reference group. No statistically significant differences in GC risk by BMI categories in subjects positive for $H$. pylori infection were observed.

\section{Difference in association between H. pylori infection and GC risk according to BMI level in the case-cohort study}

GC risk according to H. pylori infection status in stratified group by BMI level was also conducted (Table 4). In the group with $\mathrm{BMI}<23 \mathrm{~kg} / \mathrm{m}^{2}, H$. pylori infection was associated with about 2-fold higher GC risk (HR, 2.04; 95\% CI, 1.13 to 3.70). Elevated GC risk according to H. pylori infection was also observed in group with BMI of $23-24.9 \mathrm{~kg} / \mathrm{m}^{2}$ (HR, $10.52 ; 95 \% \mathrm{CI}, 1.44$ to 76.67$)$. In contrary, there was no statistically significant difference in GC risk by $H$. pylori infection in group with $\mathrm{BMI} \geq 25 \mathrm{~kg} / \mathrm{m}^{2}$ (HR, 1.73; $95 \% \mathrm{CI}, 0.78$ to 3.82). Even when we used other BMI categories $(<22.5,22.5$ 24.9 , and $\left.\geq 25 \mathrm{~kg} / \mathrm{m}^{2}\right)$, similar patterns on the association between $H$. pylori infection status and GC risk were observed.

\section{Sensitivity analysis by GC anatomical location}

In cardia GC analysis, the risk estimates were not calculated due to sparse GC cases (only 14 cases in total subjects), and thus the results were not shown in this paper. Only the 
results for non-cardia GC development were additionally presented in the Tables 2-4. As the result, the associations between BMI and GC risk in subgroup population without cardia GC cases, were persistent.

\section{Discussion}

About 1.3-fold increased GC risk in population with low BMI $\left(<23 \mathrm{~kg} / \mathrm{m}^{2}\right)$ was found in both total cohort and casecohort studies, but the association was marginally significant in the case-cohort study. In the case-cohort study, BMI levels showed U-shaped association with GC risk, especially in the H. pylori non-infected group: the risk of GC was higher in two different groups such as lower BMI group $\left(<23 \mathrm{~kg} / \mathrm{m}^{2}\right)$ or higher BMI group $\left(\geq 25 \mathrm{~kg} / \mathrm{m}^{2}\right)$ compared with the reference BMI group $\left(23-24.9 \mathrm{~kg} / \mathrm{m}^{2}\right)$.

A recently published large-scale cohort study in UK reported a reverse-J-shaped association between BMI and GC for the first time in Western studies [10]. This study including 5.24 million subjects and 3,337 incident GC cases reported an increased risk of GC in those with low BMI $\left(<20 \mathrm{~kg} / \mathrm{m}^{2}\right)$ as well as in obese subjects. Results from China cohort study also reported that high BMI $\left(\geq 23.31 \mathrm{~kg} / \mathrm{m}^{2}\right)$ compared to low BMI $\left(<20.32 \mathrm{~kg} / \mathrm{m}^{2}\right)$ was associated with reduced gastric non-cardia cancer risk rather than increased risk, implying significantly more elevated GC risk in low BMI group [11].

Our findings were analogous with those results above in terms of demonstrating increased GC risk in population with low BMI. However, significant associations between BMI and GC risk results were obtained only in H. pylori noninfected persons in our study. This suggests that $H$. pylori has a very strong effect on the development of GC, whereas BMI can play a modest role in the development of GC, as compared to $H$. pylori infection.

The link with gastric non-cardia cancer risk in obese population has not been fully established, and the explanation to support increased GC risk in populations with low BMI has so far been limited.

However, the increased risk of GC in obese people can be explained by biological changes, such as an increase in chronic inflammation and a decrease in immune response in obese people $[23,24]$, which lead to contributing the chronicization of inflammatory conditions and consequently go to gastric carcinogenesis. This can be induced into carcinogenesis regardless of $H$. pylori infection. The increased risk of GC in people with low BMI can be explained by the following mechanisms. Smokers are more likely to have low BMI and those with low BMI are more likely to have multiple nutrient deficiencies [25]. These conditions lead to reduction of natu- ral immunity, and in particular, the decrease of micronutrients such as vitamins A, C, and E can cause the limit of antioxidant activity, which can lead to an increase of inflammatory reaction due to oxidative stress [26,27].

Our results show that the U-shaped association of BMI with GC risk in non-infected individuals is more evident than in H. pylori infected individuals. The risk of GC in all $H$. pylori infected individuals has already risen even in the reference group (people with BMI of $23-24.9 \mathrm{~kg} / \mathrm{m}^{2}$ ) at the baseline risk of GC, due to $H$. pylori infection itself, and thus, the GC risk of the high-risk groups (those with $\mathrm{BMI}<23 \mathrm{~kg}$ / $\mathrm{m}^{2}$ or those with $\mathrm{BMI} \geq 25 \mathrm{~kg} / \mathrm{m}^{2}$ ) does not seem to rise much compared to the reference group. Conversely, in the H. pylori non-infected individuals, the effect of BMI itself on GC risk appears to be clearly demonstrated because major carcinogenic factor, $H$. pylori infection, are not involved. In other words, the $H$. pylori infection, a big carcinogenic factor, may obscure the risk of GC by BMI in infected individuals due to "Umbrella effect" by infection, whereas the effect of BMI on GC risk is clearly expressed in non-infected individuals because of no "Umbrella effect" by infection. This may be due to the fact that the effect of BMI is too weak for the development of GC compared to the effect of H. pylori infection.

This study has some limitations. First, the number of incident GC cases was relatively small, limiting the statistical power in stratified analysis. Though we found U-shaped relationship between BMI and GC risk in subjects not infected by $\mathrm{H}$. pylori, only one GC case was included in the reference group. Therefore, point estimate of GC risk by BMI in H. pylori non-infected group might be overestimated. Second, total energy expenditure or nutritional status was not considered, because of insufficient information on food consumption. Third, BMI information was based on height and weight measured at the time of enrollment, only, and information of BMI change during follow-up time could not be taken into account. Fourth, the results in the H. pylori $\operatorname{IgG~Ab}$ test is limited because if the $\operatorname{IgG} \mathrm{Ab}$ test is positive, it does not mean an active infection because it is seen as positive in both past and current infections. Fifth, in this cohort, 4.1\% GC cancer cases were detected by death certificate only (DCO) (=22 DCO / 485 total GC cases). Of total 463 GC cases after excluding DCO cases, GC cases with no T-Code were $26(5.7 \%)$ and those with unspecified anatomical location (C169) were $66(16.3 \%)$. A prior paper presenting the classification cardia and non-cardia GC in hospital setting reported the unspecified GC cases were 25\% ( $\mathrm{n}=50 / 200$ cases) [28]. The DCO occurs due to the gap between the coverage years of cancer registration data and those of death certificate data. This KMCC data was first linked to cancer registry, death certificate, and health insurance data (with confirmation using medical record survey) in 2001. We found that those 
who were identified as confirmed cancer cases in the secondary data in 2001 were not confirmed in recent data. The reason is because each institution had limited the retention year of data. The other reason of DCO is due to incompleteness of secondary data, such as the year of the application of the secondary data source. In estimating the cancer incidence and mortality rates reported by the WHO Globocan, the completeness of the data is evaluated by the DCO (\%) of each country (http://gco.iarc.fr/).

This study has several strengths. It was designed as a prospective cohort study and a case-cohort study. Both studies are based on prospectively collected data, thus time sequence between exposure and outcome is considered in these study designs, which minimizes reverse causation. Matching between cases and controls was not carried out in the casecohort study design; thus, effects of age or sex on development of disease could be studied on the incidence of disease in the study population. Unlike most previous published studies on the association between BMI and GC which were conducted in Western population, this study was conducted on an East Asian population. Therefore, this study was appropriate to assess the association between BMI and gastric noncardia cancer. H. pylori infection status, a potential confounder, was also adjusted in the case-cohort study.

In conclusion, this study suggests that BMI levels are associated with GC risk in a U-shaped fashion, especially in population without $H$. pylori infection.

\section{Electronic Supplementary Material}

Supplementary materials are available at Cancer Research and Treatment website (https://www.e-crt.org).

\section{Conflicts of Interest}

Conflict of interest relevant to this article was not reported.

\section{Acknowledgments}

This work was supported by the National Research Foundation of Korea (NRF) grant funded by the Korea government (MSIP) (No. NRF-2016R1A2B4014552) and by the Korean Foundation for Cancer Research (No. KFCR-CB-2013-01).

\section{Author Details}

${ }^{1}$ Department of Preventive Medicine, Seoul National University College of Medicine, Seoul, ${ }^{2}$ Cancer Research Institute, Seoul National University, Seoul, ${ }^{3}$ Department of Biomedical Science, Seoul National University Graduate School, Seoul, ${ }^{4}$ Department of Public Health, Graduate School, The Catholic University of Korea, Seoul, Korea, ${ }^{5}$ Department of Medical Epidemiology and Biostatistics, Karolinska Institutet, Stockholm, Sweden, ${ }^{6}$ Department of Community Medicine, Faculty of Health Sciences, University of Tromsø, The Arctic University of Norway, Tromsø, " Department of Research, Cancer Registry of Norway - Institute of Population-Based Cancer Research, Oslo, Norway, ${ }^{8}$ Genetic Epidemiology Group, Folkhälsan Research Center, Helsinki, ${ }^{9}$ Faculty of Medicine, University of Helsinki, Helsinki, Finland, ${ }^{10}$ Department of Preventive Medicine, Konkuk University, Chungju, Korea, ${ }^{11}$ Non-communicable Disease and Health Promotion, Western Pacific Regional Office, World Health Organization, Manila, Philippines, ${ }^{12}$ Department of Cancer Control and Population Health, Graduate School of Cancer Science \& Policy, National Cancer Center, Goyang, ${ }^{13}$ Cancer Risk Appraisal and Prevention Branch, National Cancer Control Institute, National Cancer Center, Goyang, ${ }^{14}$ The Armed Forces Capital Hospital, Seongnam, Korea

\section{References}

1. Ferlay J, Soerjomataram I, Dikshit R, Eser S, Mathers C, Rebelo $\mathrm{M}$, et al. Cancer incidence and mortality worldwide: sources, methods and major patterns in GLOBOCAN 2012. Int J Cancer. 2015;136:E359-86.

2. Soerjomataram I, Lortet-Tieulent J, Parkin DM, Ferlay J, Mathers C, Forman D, et al. Global burden of cancer in 2008: a systematic analysis of disability-adjusted life-years in 12 world regions. Lancet. 2012;380:1840-50.

3. Jung KW, Won YJ, Oh CM, Kong HJ, Lee DH, Lee KH, et al. Cancer statistics in Korea: incidence, mortality, survival, and prevalence in 2014. Cancer Res Treat. 2017;49:292-305.

4. Nguyen DM, El-Serag HB. The epidemiology of obesity. Gastroenterol Clin North Am. 2010;39:1-7.
5. Calle EE, Kaaks R. Overweight, obesity and cancer: epidemiological evidence and proposed mechanisms. Nat Rev Cancer. 2004;4:579-91.

6. Abnet CC, Freedman ND, Hollenbeck AR, Fraumeni JF Jr, Leitzmann M, Schatzkin A. A prospective study of BMI and risk of oesophageal and gastric adenocarcinoma. Eur J Cancer. 2008;44:465-71.

7. Corley DA, Kubo A, Zhao W. Abdominal obesity and the risk of esophageal and gastric cardia carcinomas. Cancer Epidemiol Biomarkers Prev. 2008;17:352-8.

8. Merry AH, Schouten LJ, Goldbohm RA, van den Brandt PA. Body mass index, height and risk of adenocarcinoma of the oesophagus and gastric cardia: a prospective cohort study. 
Gut. 2007;56:1503-11.

9. Chen Y, Liu L, Wang X, Wang J, Yan Z, Cheng J, et al. Body mass index and risk of gastric cancer: a meta-analysis of a population with more than ten million from 24 prospective studies. Cancer Epidemiol Biomarkers Prev. 2013;22:1395-408.

10. Bhaskaran K, Douglas I, Forbes H, dos-Santos-Silva I, Leon DA, Smeeth L. Body-mass index and risk of 22 specific cancers: a population-based cohort study of 5.24 million UK adults. Lancet. 2014;384:755-65.

11. Fan JH, Wang JB, Wang SM, Abnet CC, Qiao YL, Taylor PR. Body mass index and risk of gastric cancer: a 30-year followup study in the Linxian general population trial cohort. Cancer Sci. 2017;108:1667-72.

12. Wayman J, Forman D, Griffin SM. Monitoring the changing pattern of esophago-gastric cancer: data from a UK regional cancer registry. Cancer Causes Control. 2001;12:943-9.

13. Bray F, Ferlay J, Laversanne M, Brewster DH, Gombe Mbalawa C, Kohler B, et al. Cancer incidence in five continents: inclusion criteria, highlights from Volume $\mathrm{X}$ and the global status of cancer registration. Int J Cancer. 2015;137:2060-71.

14. Colquhoun A, Arnold M, Ferlay J, Goodman KJ, Forman D, Soerjomataram I. Global patterns of cardia and non-cardia gastric cancer incidence in 2012. Gut. 2015;64:1881-8.

15. IARC Working Group on the Evaluation of Carcinogenic Risks to Humans. Schistosomes, liver flukes and Helicobacter pylori. IARC monographs on the evaluation of carcinogenic risks to humans. Vol. 61. Lyon: International Agency Research on Cancer; 1994.

16. Argent RH, Hale JL, El-Omar EM, Atherton JC. Differences in Helicobacter pylori CagA tyrosine phosphorylation motif patterns between western and East Asian strains, and influences on interleukin-8 secretion. J Med Microbiol. 2008;57(Pt 9): 1062-7.

17. Lender N, Talley NJ, Enck P, Haag S, Zipfel S, Morrison M, et al. Review article: associations between Helicobacter pylori and obesity: an ecological study. Aliment Pharmacol Ther.
2014;40:24-31.

18. Yoo KY, Shin HR, Chang SH, Lee KS, Park SK, Kang D, et al. Korean multi-center cancer cohort study including a biological materials bank (KMCC-I). Asian Pac J Cancer Prev. 2002;3:8592.

19. World Health Organization. Obesity: preventing and managing the global epidemic: report on a WHO consultation. No. 894. Geneva: World Health Organization; 1997.

20. Yamaoka Y. Mechanisms of disease: Helicobacter pylori virulence factors. Nat Rev Gastroenterol Hepatol. 2010;7:629-41.

21. Park CY, Cho YK, Kodama T, El-Zimaity HM, Osato MS, Graham DY, et al. New serological assay for detection of putative Helicobacter pylori virulence factors. J Clin Microbiol. 2002;40: 4753-6.

22. Barlow WE, Ichikawa L, Rosner D, Izumi S. Analysis of casecohort designs. J Clin Epidemiol. 1999;52:1165-72.

23. Monteiro R, Azevedo I. Chronic inflammation in obesity and the metabolic syndrome. Mediators Inflamm. 2010;2010: 289645.

24. Marti A, Marcos A, Martinez JA. Obesity and immune function relationships. Obes Rev. 2001;2:131-40.

25. Bird JK, Murphy RA, Ciappio ED, McBurney MI. Risk of deficiency in multiple concurrent micronutrients in children and adults in the United States. Nutrients. 2017;9:E655.

26. Kong P, Cai Q, Geng Q, Wang J, Lan Y, Zhan Y, et al. Vitamin intake reduce the risk of gastric cancer: meta-analysis and systematic review of randomized and observational studies. PLoS One. 2014;9:e116060.

27. Reuter S, Gupta SC, Chaturvedi MM, Aggarwal BB. Oxidative stress, inflammation, and cancer: how are they linked? Free Radic Biol Med. 2010;49:1603-16.

28. Dolan K, Sutton R, Walker SJ, Morris AI, Campbell F, Williams EM. New classification of oesophageal and gastric carcinomas derived from changing patterns in epidemiology. Br J Cancer. 1999;80:834-42. 